\title{
Multiple Antimicrobial Resistance of Extended Spectrum Beta-Lactamase-Producing Escherichia coli from Small-Scaled Poultry Farms and Retail Chicken
}

\author{
Agnes Kilonzo-Nthenge ${ }^{1,2}$, Samuel Nahashon ${ }^{2}$, Siqin Liu², Ravneet Sandhu² and KourtneyDaniels ${ }^{2}$ \\ 1. Department of Human Sciences, Tennessee State University, 3500 John A. Merritt Boulevard, Nashville, Tennessee 37209 \\ 2. Department of Agricultural and Environmental Sciences, Tennessee State University, 3500 John A. Merritt Blvd., Nashville,
} Tennessee 37209, USA

\begin{abstract}
Antibiotics used for agricultural purpose has contributed to the increased prevalence of antibiotic-resistant bacteria. The goal of this study was to investigate the prevalence and antimicrobial resistance of ESBL-producing E. coli in small-scaled poultry farms and retail chicken. The cultured $E$. coli isolates were subjected to phenotypic tests, susceptibility tests, and the polymerase chain reaction for detection of $b l a_{\mathrm{CTX}-\mathrm{M}}, b l a_{\mathrm{SHV}}$, and $b l a_{\mathrm{TEM}}$ genes. From 120 samples each of chicken feces, retail chicken, soil and chicken feed, ESBL-producing E. coli isolates were detected in 75.9\%, 63.6\%, 39.2\%, and 13.3\% of the samples, respectively. Minimum inhibitory concentration (MICs) values indicated that ESBL-producing E. coli were resistance to ampicillin (MIC $\geq 32$ $\mu \mathrm{g} / \mathrm{mL}$ ), gentamicin (MIC $\geq 16 \mu \mathrm{g} / \mathrm{mL}$ ), cefotaxime (MIC $\geq 4 \mu \mathrm{g} / \mathrm{mL}$ ) and ceftriaxone (MIC $\geq 4 \mu \mathrm{g} / \mathrm{mL}$ ), respectively. The total resistance for imipenem was also observed at $1.0 \%$ (MIC $\geq 4 \mu \mathrm{g} / \mathrm{mL}$ ) and none of the isolates were resistant to ceftazidime (MIC $\geq$ $16 \mu \mathrm{g} / \mathrm{mL}$ ). ESBL-producing $E$. coli from chicken feces and retail chicken carried bla $a_{\mathrm{SHV}}$ gene at a rate of $6.8 \%$ and $5.7 \%$, respectively and $b l a_{\text {Стх-м }}$ gene was also revealed at $2.9 \%$ in retail chicken. Moreover, ESBL-producing E. coli isolated from soil harbored $b l a_{\mathrm{SHV}}$ and $b l a_{\mathrm{CTX}-\mathrm{M}}$ genes at $5 \%$. None of the feed samples yielded ESBLs genes. Twenty three resistance patterns were observed for multi-resistant ESBL-producing E. coli. This study highlights the prevalence of multi-antimicrobial resistant ESBL-producing E. coli in small-scaledpoultry farms and retail chicken, hence the need to review poultry management practices to minimize the occurrence.
\end{abstract}

Key words: $E$. coli, $\beta$-lactamases, poultry farms, retail chicken.

\section{Introduction}

Several findings suggest that the misuse of antimicrobials in animals' production results to antimicrobial resistant bacteria that could find their path into the environment [1]. Escherichia coli found in the gastrointestinal tract of human and animals are harmless, however that causes a number of significant illnesses [2]. E. coli, a zoonotic and a widespread Enterobacteriaceae is linked to animal and human infections [3] and also reflected as an indicator of fecal contamination in food. E. coli resides in soil,

Corresponding author: Agnes Kilonzo-Nthenge, Ph.D., associate professor, research fields: food microbiology and food safety. water, farm animals, and food products [4] and is known to produce extended spectrum ß-lactamases (ESBLs) [5] which exhibit effective hydrolyzation of $\beta$-lactam antibiotics. Beta-lactam resistance is caused by ESBL genes that are encoded by plasmid [6]. According to Habeeb et al. [7], the resistance usually depends on expression of bla genes belonging to the inter alia $\left.b l a_{\mathrm{TEM}}\right)$, SHV $b l a_{\mathrm{SHV}}$ and $b l a_{\mathrm{CTX}-\mathrm{M}}$ genes family. Management for E. coli infections has been progressively complicated by the emergence of resistance to most first-line antimicrobial agents such as cephalosporins [8]. Cephalosporins, particularly third and fourth-generation are essential antimicrobial drugs in human and animal medicine [9]. The rising of Enterobacteriaceae resistance to cephalosporins over 
the years is indebted to the spreading of ESBLs [10].

Evidence exists that antimicrobial drugs' use in the livestock plays a significant role in the contamination of food with ESBL-producing bacteria [11]. According to Bergenholtz et al. [12], the recovery of ESBL-producing bacteria from foods and animals has been reported and this has caused major and significant attention to the food industry [13]. In view of the accumulative concerns of ESBL-producing $E$. coli and the potential risk to the public health, it is important to recognize the potential reservoirs of ESBL-producing E. coli in agricultural settings. ESBL-producing E. coli may be used to trace the spread of antibiotic resistant bacteria [14] in the environment and food chain. Thus, this study focused on the search for ESBL-producing E. coli and confirmation thereof through the PCR amplification of the $b l a_{\mathrm{CTX}-\mathrm{M}}, b l a_{\mathrm{TEM}}$, and $b l a_{\mathrm{SHV}}$ genes in small-scaled poultryfarms' environment and retail chicken. Additionally, due to the rise of Enterobacteriaceae ESBL-positive strains exhibiting multidrug-resistance, an additional objective of our study was to evaluate the sensitivity of ESBL-producing $E$. coli to a panel of antibiotics.

\section{Materials and Methods}

\subsection{Sampling of Materials}

Environmental samples tested in this study included chicken feces, soil, and feed from six poultry farms (two farms per county) in Davidson, Williamson, and Cheatham counties in Tennessee, USA. These samples were acquired at private properties and consent was granted by the collaborating poultry farms. In the current study, small-scaled poultry farms raising the commercial chicken layer variety Single Comb White Leghorn were defined as those rearing 20 to 250 birds and vended their products to farmer's markets, roadside stands, or had direct delivery to their clients. In addition, retail chicken was purchased from 6 chain supermarkets in Davidson County. To keep confidentiality, the farms and stores were identified by ID numbers, sample type, date and source of collection.

\subsection{Isolation of Escherichia coli}

Conventional poultry farms were sampled for chicken semi-fresh droppings, feed, and soil within the farm vicinity. All samples were collected over a 10 month period (February 2016-November 2016). For each sample type, five sub-samples were collected and pooled to make one composite sample (i.e., 5 samples per composite). Two samples for each environmental sample from all six farms were collected once in a month and analyzed for E. coli. At the same time, retail chicken was purchased from six different grocery stores. In total, 480 samples (feces $=120$; soil $=120$, feed $=120$, retail chicken $=120$ ) were analyzed . The background information of drugs used on farms was unknown; farmers were reactant to display farm records. Samples were processed in the laboratory within $24 \mathrm{~h}$ of collection or were stored overnight at $4^{\circ} \mathrm{C}$ until processed the next day. Briefly, 25 grams of each sample were suspended in $225 \mathrm{~mL}$ LB (Luria-Bertani) broth (Becton, Dickinson and Company, USA) and homogenized (Stomacher 400 circulator, Seward, London, UK) at $230 \mathrm{rpm}$ for 2 minutes. The homogenates were incubated at $37{ }^{\circ} \mathrm{C}$ for $20 \mathrm{~h}$. Subsequently, $10 \mu \mathrm{L}$ were streaked on MacConkey agar (MAC; BD, Franklin Lakes, NJ) plates and sub cultured onto Eosin Methylene Blue (EMB; BD, Franklin Lakes, NJ) agar plates at $37{ }^{\circ} \mathrm{C}$ for $24 \mathrm{~h}$. Colonies that exhibited a dark blue color with characteristic metallic sheen were selected and identified as $E$. coli by oxidase test and the API 20E (bioMérieux, Hazelwood, MO).

\subsection{Isolation of ESBL-Producing Escherichia coli}

E. coli isolates identified at $98 \%$ and above confidence level by API 20E test were tested for ESBL production. To screen for ESBL-producing $E$. coli, isolates were cultured in nutrient broth $(\mathrm{BD}$, Franklin Lakes, NJ) for $20 \mathrm{~h}$ at $37^{\circ} \mathrm{C}$. Subsequently, 
$10 \mu \mathrm{L}$ of grown cultures were streaked on CHROMID ESBL selective chromogenic media (bioMérieux, Hazelwood, MO) and incubated for $18-20 \mathrm{~h}$ at $37^{\circ} \mathrm{C}$. Presence of ESBL production was confirmed by combination disc method for ESBL detection. For this purpose, antibiotic susceptibility disks (BBL, BD) containing cefotaxime $(30 \mu \mathrm{g})$ and ceftazidime $(30 \mu \mathrm{g})$ with or without clavulanic acid $(10 \mu \mathrm{g})$ were used. Briefly, overnight LB broth cultures were adjusted to a 0.5 McFarland opacity standard (BD, Franklin Lakes, NJ) and evenly streaked onto Mueller-Hinton agar (MHA) (Remel, Lenexa, KS) plates to form a lawn culture. After $10 \mathrm{~min}$ at ambient temperatures, third generation cephalosporins with and without clavulanic acid were placed onto inoculated plates and incubated at $37{ }^{\circ} \mathrm{C}$ for $18 \mathrm{~h}$. A difference in the zone of inhibition of $\geq 5 \mathrm{~mm}$ for cefotaxime and ceftazidime with and without clavulanic acid was considered to indicate ESBL producing E. coli. The E. coli ATCC 25922 was used as the reference strain.

\subsection{Minimum Inhibitory Concentrations (MIC) for ESBL-Producing Escherichia coli}

MICs for ESBL-producing E. coli $(\mathrm{n}=105)$ against selected cephalosporins, carbapenem, and aminoglycoside were determined by E-test (gradient methods) and agar dilution (reference method) according to Clinical and Laboratory Standards Institute (CLSI) guidelines [15]. E-test strips were purchased from Sigma-Aldrich (St. Louis, MO, USA). MICs were documented by determining where the ellipse edge intersected with the strip (MIC reading scale in $\mu \mathrm{g} / \mathrm{mL}$ ). Briefly, selected E. coli colonies from an overnight agar plates were emulsified in $0.85 \% \mathrm{NaCl}$ to achieve a turbidity equivalent to a 0.5 McFarland standard. The suspensions were swabbed on a MHA plates and allowed to dry for 15 minutes. E-test strips were then applied to the agar surface with sterile forceps and incubated at $37{ }^{\circ} \mathrm{C}$ for $18-20 \mathrm{~h}$. The resistance was interpreted as $\mathrm{S}$ (Susceptible), I (Intermediate) or R (Resistant) by comparing the breakpoint values of each antibiotic with the CLSI recommended criteria [15]. K. pneumonia ATCC 700603 and E. coli ATCC 25922 were used as controls strains.

\subsection{Detectionand PCR Confirmation of b-Lactamase} Genes in ESBL-Producing Escherichia coli

Presumptive ESBL-producing E. coli was confirmed through amplification of the $b l a_{\mathrm{CTX}-\mathrm{M} \text {, }}$ $b l a_{\mathrm{TEM}}$ and $b l a_{\mathrm{SHV}}$ genes using PCR assays. In total 105 ESBL-producing E. coli isolates were randomly selected and utilized for bla gene detection by PCR. The isolates were cultivated overnight in Tryptic Soy Broth (Difco Dickinson and Company, Sparks, MD) to $>5 \times 10^{6}$ cells and $1 \mathrm{~mL}$ of the overnight culture was centrifuged for $3 \mathrm{~min}$ at $13,000 \times \mathrm{g}$ at $4{ }^{\circ} \mathrm{C}$. DNA was isolated using the Pure link Genomic DNA Mini Kit (Life Technologies, Grand Island, New York) and respective concentrations were measured using a NanoDrop 2000 (Thermo Scientific, Pittsburgh, PA). Template DNA was diluted to a final working concentration of $25 \mathrm{ng} / \mu \mathrm{L}$ and its integrity was confirmed using agarose gel electrophoresis. Primer sequences, their melting temperature and expected size of amplicons of the $b l a_{\mathrm{CTX}-\mathrm{M}}, b l a_{\mathrm{TEM}}$ and $b l a_{\mathrm{SHV}}$ genes first reported by Feizabadi et al. [16] and Mahrouki et al. [17] are presented in Table 1. Using a PCR CORE Kit (Sigma, St. Louis, MO), PCR reactions were carried out in a final volume of $25 \mu \mathrm{L}$ consisting of $125 \mathrm{ng}$ DNA template, $2.5 \mu \mathrm{L}$ 10X PCR buffer containing $10 \mathrm{mM}$ Tris- $\mathrm{HCl}$ (PH 8.3), $3 \mathrm{mM}$ $\mathrm{MgCl}_{2}, 400 \mu \mathrm{M}$ dNTPs, 2.5 UTaq DNA polymerase, $0.5 \mu \mathrm{M}$ each forward and reverse primer and deionized $\mathrm{H}_{2} \mathrm{O}$. Amplification was carried out in an Eppendorf Mastercycler nexus GSX1 thermal cycler (Fisher Scientific, Fair Lawn, NJ, USA) following thermal cycling profile adapted from Seyedjavadi et al. [18] for each $b l a_{\mathrm{TEM}}$, bla $\mathrm{a}_{\mathrm{SHV}}$ and $b l a_{\mathrm{CTX}-\mathrm{M}}$ primers as follows: Initial denaturation at $94{ }^{\circ} \mathrm{C}$ for 5 minutes, 35 cycles of amplification at $94{ }^{\circ} \mathrm{C}$ for 45 seconds, $54{ }^{\circ} \mathrm{C}$ for 30 seconds, and $72{ }^{\circ} \mathrm{C}$ for 1 minute; initial 
Table 1 Oligonucleotide primers used to amplify the bla genes of the ESBL-producing $E$. coli isolated from small-scaled poultry farms.

\begin{tabular}{|c|c|c|c|c|}
\hline Gene target & Nucleotide sequence & $\mathrm{TM}^{\mathrm{a}}$ & Product size (bp) & Reference \\
\hline \multirow{2}{*}{$b l a_{\mathrm{CTX}-\mathrm{M}}$} & 5-ACGCTGTTGTTAGGAAGTG-3 & 58 & \multirow{2}{*}{857} & \multirow{2}{*}[16]{} \\
\hline & 5-TTGAGGCTGGGTGAAGT-3 & 57 & & \\
\hline \multirow{2}{*}{$b l a_{\mathrm{TEM}}$} & 5-TCGGGGAAATGTGCGCG-3 & 62 & \multirow{2}{*}{972} & \multirow{2}{*}{ [17] } \\
\hline & 5-TGCTTAATCAGTGAGGCACC-3 & 60 & & \\
\hline \multirow{2}{*}{$b l a_{\mathrm{SHV}}$} & 5-GGGTTATTCTTATTTGTCGC-3 & 56 & \multirow{2}{*}{615} & \multirow{2}{*}{ [16] } \\
\hline & 5-TTAGCGTTGCCAGTGCTC-3 & 60 & & \\
\hline
\end{tabular}

${ }^{\mathrm{a}}$ Melting temperature.

denaturation at $94{ }^{\circ} \mathrm{C}$ for 5 minutes, 30 cycles of amplification at $94{ }^{\circ} \mathrm{C}$ for 45 seconds, $56{ }^{\circ} \mathrm{C}$ for 1 minute, and $72{ }^{\circ} \mathrm{C}$ for 1 minute; Initial denaturation at $94{ }^{\circ} \mathrm{C}$ for 5 minutes, 36 cycles of amplification at $94{ }^{\circ} \mathrm{C}$ for 1 minute, $58{ }^{\circ} \mathrm{C}$ for 30 seconds, and $72{ }^{\circ} \mathrm{C}$ for 1 minute, respectively. Each of these reactions was followed by a final extension at $72{ }^{\circ} \mathrm{C}$ for 10 minutes. Samples were held at $4{ }^{\circ} \mathrm{C}$ until further use. Negative control reactions were prepared for each primer to identify contamination from reactions with DNA that was not targeted. After PCR amplification of the genes, PCR products were analyzed by electrophoresis in a $1.2 \%$ agarose gel (Fisher Scientific, Fair Lawn, NJ, USA) stained with $50 \mu$ g ethidium bromide. The PCR products were separated in a $1 \times$ TBE buffer in a Fisher Biotech gel electrophoresis system (Fisher Scientific, Fair Lawn, NJ, USA) at 100 volts for 2 hours. K. pneumonia ATCC 7000603 and E. coli ATCC 25922 were used as positive and negative controls, respectively.

\subsection{ESBL-Producing Escherichia coli Antibiotic Susceptibility Test}

Antibiotic susceptibility testing of ESBL-producing E. coli isolates $(\mathrm{n}=105)$ was done by Kirby Bauer disk diffusion method and according to the CLSI [15]. Briefly, overnight LB cultures for ESBL-producing $E$. coli isolates were adjusted to $0.5 \mathrm{McF}$ arland standards and spread evenly on MHA plates and incubated at 37 ${ }^{\circ} \mathrm{C}$ for $24 \mathrm{~h}$; commercially available antibiotic disks (St. Louis, MO, USA) were used for antimicrobial susceptibility testing. The panel of 12 different antimicrobial drugs included: amikacin $(30 \mu \mathrm{g})$, ciprofloxacin $(5 \quad \mu g)$, erythromycin, $(15 \mu g)$, chloramphenicol $(30 \mu \mathrm{g})$, kanamycin $(30 \mu \mathrm{g})$, streptomycin $(10 \mu \mathrm{g})$, novobioxn $(30 \mu \mathrm{g})$, nalidixic acid $(30 \mu \mathrm{g})$, tetracycline $(30 \mu \mathrm{g})$, vancomycin $(30 \mu \mathrm{g})$, colistin $(10 \mu \mathrm{g})$, and amoxicillin $(30 \mu \mathrm{g})$. E. coli ATCC 25922 was used as positive reference strain in all tests.

\subsection{Statistical Analyses}

Differences in mean prevalence and antimicrobial resistance of the ESBL-producing E. coli from poultry feces, retail chicken, soil and feed were determined by a one-way analysis of variance using SPSS software for Windows, version 12 (SPSS, IBM, Armonk, NY) and the chi-square test, respectively. Results for all analyses were considered significant at $p<0.05$.

\section{Results and Discussion}

\subsection{Escherichia coli Isolates}

Biochemically confirmed E. coli was detected in $87.1 \%$ (418 out of 480 ) of various samples as listed in Table 2. In this work, chicken feces were highly (96.7\%) contaminated and this demonstrates that poultry feces are reservoirs E. coli [19]. Likewise, $91.7 \%$ of the retail chicken samples were also contaminated with E. coli, however not statistically different from chicken feces $(p>0.05)$. There is a continuous defecation of $E$. coli by birds with the probability of contaminating the environment and entering the food chain. Through excretion, E. coli can potentially be transferred to agricultural products by avian manure to humans [20]. The practice of spreading contaminated chicken litter as a soil amendment 
Table 2 Incidence of antimicrobial resistant $E$. coli from small poultry farms and retail chicken.

\begin{tabular}{llll}
\hline Sample type & No. of samples & $\begin{array}{l}\text { Incidence of E. coli } \\
(\%), 95 \% \text { CI }\end{array}$ & $\begin{array}{l}\text { Incidence of ESBL-producing } \\
\text { E. coli }(\%), 95 \% \text { CI }\end{array}$ \\
\hline Chicken feces & 120 & $116(96.7)^{\mathrm{a}}$ & $88(75.9)^{\mathrm{a}}$ \\
Retail chicken & 120 & $110(91.7)^{\mathrm{ab}}$ & $70(63.6)^{\mathrm{a}}$ \\
Soil & 120 & $102(85)^{\mathrm{b}}$ & $40(39.2)^{\mathrm{b}}$ \\
Feed & 120 & $90(75)^{\mathrm{c}}$ & $12(13.3)^{\mathrm{c}}$ \\
Total No. of samples & 480 & 418 & 210 \\
\hline
\end{tabular}

may also result to $E$. coli entering water that is used for drinking and irrigation of crops. Our results are in agreement with an earlier finding that meats are a common source of $E$. coli [21]. The contamination of poultry meats arising from slaughter process is often primarily of fecal origin, due to intestinal leakage of fowls. Additionally, poultry meat may also be adulterated during processing, and transportation to the retail stores [22]. Transfer of bacteria from poultry products to human population may occur through the consumption or handling of contaminated meats [23]. Therefore, consumers should follow good hygienic practices during cooking and meal preparation, especially when raw chicken is an ingredient.

Soils within the vicinity of the poultry farms displayed E. coli contamination at a rate of $85 \%$. Trawińska et al. [24] assessed E. coli contamination of the environment surrounding the poultry farms and established that the highest count was in the soil samples. Previous reports have demonstrated that poultry manure used for field application or rinse water during cleaning can be a source of entrance of bacteria into the soil environment [25]. Other avenues would include air transmission or spread by poultry house workers from contaminated floors to the outdoors. Our study also revealed $75 \%$ prevalence of $E$. coli in the poultry feed. This highlights the need for sanitary handling of poultry feed during processing, transpiration, and storage; since animal feed is at the begging of the food safety chain. Bacteria can readily diffuse to food animals via tainted feed and potentially contaminate animal carcasses intended for human consumption [26].

\subsection{Prevalence of ESBL-Producing Escherichia coli}

Understanding the frequency of ESBL-positive bacteria is quite significant, particularly that infections caused by these bacteria are more challenging to treat in humans. This study demonstrated a high prevalence of ESBL-producing E. coli (75.9\%) in chicken feces from small-scale poultry farms (Table 2). In contrast to our results, ESBL-producing E. coli has been previously reported in broiler fecal samples at a lower rate of $42.1 \%$ [27]. The abundance and the movement of antibiotic resistance bacteria in agricultural soils may be enhanced by the application of animal manures that contain antibiotic resistant bacteria [28]. It is important to uphold environmental hygiene principles, notably with reverence to ensuring that crops do not come into contact with antimicrobial resistant pathogens carried in raw manure that is used as a fertilizer. The uptake of these antimicrobial resistant bacteria by vegetables that are consumed raw can cause imminent risk to the health of the consumer.

ESBL-producing $E$. coli frequency among retail chicken was $63.6 \%$ in our study. This is in agreement with a study in Portugal [29] where ESBL-producing E. coli was isolated in $60 \%$ from chicken carcasses at the retail level. In contrast to these results, ESBL-positive E. coli was notably lower compared to previous studies by Egea et al. [30] and Cohen et al. [31], which reported $93.3 \%$ and $94 \%$ contamination of raw poultry meat, respectively. It is a concern that ESBL producing E. coli is found in retail chicken, this bacteria hydrolyses several antibiotics, including third-generation cephalosporin [32] which is critical in managing infections. 
In total, $39.2 \%$ of all soil samples from poultry farms turned out to be positive for ESBL-producing $E$. coli. However, the isolation rate was lower as compared to $77.0 \%$ observed in a previous study [33]. The prevalence of ESBL-producing E. coli in animal farms could also affect public health through environmental pollution [34]. According to Laube et al. [35], ESBL-producing E. coli has been detected on the land adjacent to animal farms. Soil is reported to harbor a diversity of microorganisms that are considered potential reservoirs for antibiotic resistance [36]. Overall, 13.3\% ESBL-producing E. coli was isolated from poultry feed, significantly $(p<0.05)$ lower as compared to bacteria found in chicken feces, retail chicken, and soil. In some farms, antimicrobials are routinely added to animal feeds, thus repetitively exposing bacterial populations to sub therapeutic doses; ideal for the emergence and spread of antimicrobial resistance [37]. Therefore, effort must be made towards withdrawing the use of essential antimicrobial drugs in agriculture and strictly practice the therapeutic use under the oversight of veterinarians [38].

\subsection{MICs for ESBL-Producing Escherichia coli}

The MICs for ESBL-producing E. coli from various sources are detailed in Table 3. Our analysis showed ESBL-producing E. coli resistance to cephalosporins (cefotaxime cefoxitin, cefritaxone), carbapenem (imipenem), aminoglycoside (gentamicin), and penicillin (ampicillin). The MIC determination revealed that $12.4 \%$ and $3.9 \%$ of the isolates had MIC values of $\geq 4 \mu \mathrm{g} / \mathrm{mL}$ to both cefotaxime and ceftriaxone; thus confirming resistance to third generation cephalosporin (Table 3). It was also observed that $57.1 \%$ isolates were resistant to ampicillin (MIC $\geq 32 \mu \mathrm{g} / \mathrm{mL}$ ) and $51.4 \%$ were resistant to gentamicin (MIC $\geq 16 \mu \mathrm{g} / \mathrm{mL}$ ). The lowest rates of resistance in ESBL-producing isolates were observed for ceftazidime $0 \%$ (MIC $\geq 16 \mu \mathrm{g} / \mathrm{mL}$ ) and imipenem $1.0 \%$ (MIC $\geq 4 \mu \mathrm{g} / \mathrm{mL}$ ). Although few
ESBL-producing E. coli isolates were resistant to imipenem, it is still a concern since this antimicrobial agent is commonly used in human medicine [39]. According to Samaha-Kfoury and Araj [40], the treatment of ESBL-producing bacteria is limited to carbapenems such as imipenem. Moreover, our findings exhibited resistance among $E$. coli isolates to penicillin which is used routinely in the treatment of urinary tract infection [18]. More disturbing, ESBL-producing $E$. coli has been documented to be resistant to clinically essential b-lactam antibiotics including third and fourth-generation cephalosporins and penicillins [41]. Carcasses are often contaminated with resistant E. coli [42] at slaughter and probably, ESBL-producing E. coli and may be transmitted to humans through the consumption of contaminated chicken. Of note, ESBL-producing E. coli isolates were resistant to ampicillin and cefotaxime. The resistance to these antibiotics may be largely linked with the frequently use of ampicillin and cefotaxime in local human and animal clinical practices [43]. Our study provides evidence that poultry farms and retail chicken should be reflected as an important reservoir of ESBL-producing E. coli.

\subsection{Occurrence of bla $a_{\mathrm{CTX}-\mathrm{M}}, b a_{\mathrm{TEM}}$ and bla $a_{\mathrm{SHV}}$ Genes}

This study revealed that ESBL-producing E. coli from small-scale poultry farms and retail chicken harbored $b l a_{\mathrm{CTX}-\mathrm{M}}, \quad b l a_{\mathrm{TEM}}$ and $b l a_{\mathrm{SHV}}$ genes. A representation of PCR amplification for the genes is shown in Fig. 1. About 6.8\% (3 of 44) of ESBL-producing E. coli isolates from chicken feces and $5.7 \%$ (2 of 35 ) from retail chicken carried the $b l a_{\mathrm{SHV}}$ gene. On the other hand, gene $b a_{\text {СтХ-м }}$ was detected at 2.9\% (1 of 35) bacteria isolates from retail chicken. The $b l a_{\mathrm{SHV}}$ and $b l a_{\mathrm{CTX}-\mathrm{M}}$ were both detected in soils at $5 \%$ (1 of 20) of sample isolates. E. coli strains producing CTX-M enzymes have been reported to be the most frequent ESBL-positive Enterobacteriaceae detected in humans [44]. None of the isolates showed the presence of any combination 
Table 3 ESBL-producing Escherichia coli resistance to cephalosporins, carbapenem, and aminoglycoside.

\begin{tabular}{|c|c|c|c|c|c|c|c|c|c|c|c|c|c|c|c|c|c|c|c|}
\hline \multirow{2}{*}{$\begin{array}{l}\text { Antimicrobial } \\
\text { agent } \\
\text { Cephalosporins } \\
\text { Cefotaxime }\end{array}$} & \multicolumn{3}{|c|}{$\begin{array}{c}\text { MIC interpretive } \\
\text { criteria }(\mu \mathrm{g} / \mathrm{mL}) \\
\text { S I R }\end{array}$} & \multirow{2}{*}{$\begin{array}{l}\text { Antibiotic } \\
\text { MIC } \mu \mathrm{g} / \mathrm{mL} \text { ) } \\
0.002-32\end{array}$} & \multicolumn{3}{|c|}{$\begin{array}{c}\text { Resistance } \\
\text { CF isolates (\%) } \\
\text { S I R }\end{array}$} & \multicolumn{3}{|c|}{$\begin{array}{c}\text { Resistance } \\
\text { RC isolates (\%) } \\
\text { S I R }\end{array}$} & \multicolumn{3}{|c|}{$\begin{array}{c}\text { Resistance } \\
\text { SL isolates (\%) } \\
\text { S I R }\end{array}$} & \multicolumn{3}{|c|}{$\begin{array}{c}\text { Resistance } \\
\text { FD isolates (\%) } \\
\text { S I R }\end{array}$} & \multicolumn{3}{|c|}{$\begin{array}{c}\text { Total resistance } \\
(\%) \\
\text { S I R } \\
\end{array}$} \\
\hline & $\leq 1$ & 2 & $\geq 4$ & & 34.3 & 4.8 & 2.9 & 23.8 & 2.9 & 6.7 & 18.1 & - & 1.0 & 3.8 & - & 1.9 & 80 & 7.6 & 12.4 \\
\hline Cefoxitin & $\leq 8$ & 16 & $\geq 32$ & $0.016-256$ & 22.9 & 11.4 & 7.6 & 29.5 & - & 3.8 & 7.6 & 8.6 & 2.9 & 1.9 & 2.9 & 1.0 & 61.9 & 22.9 & 15.2 \\
\hline Ceftriaxone & $\leq 1$ & 2 & $\geq 4$ & $0.016-256$ & 31.4 & 9.5 & 1.0 & 21.9 & 11.4 & - & 15.2 & 1.9 & 1.9 & 1.9 & 2.9 & 1.0 & 70.4 & 25.7 & 3.9 \\
\hline Ceftazidime & $\leq 4$ & 8 & $\geq 16$ & $0.016-256$ & 28.6 & 13.3 & - & 29.5 & 3.8 & - & 17.1 & 1.9 & - & 2.9 & 2.9 & - & 78.1 & 21.9 & - \\
\hline $\begin{array}{l}\text { Carbapenem } \\
\text { Imipenem }\end{array}$ & $\leq 1$ & 2 & $\geq 4$ & $0.002-32$ & 38.1 & 2.9 & 1.0 & 33.3 & - & - & 19.0 & - & - & 5.7 & - & - & 96.2 & 2.9 & 1.0 \\
\hline $\begin{array}{l}\text { Aminoglycoside } \\
\text { Gentamicin }\end{array}$ & $\leq 4$ & 8 & $\geq 16$ & $0.19-96$ & 8.6 & 9.5 & 23.8 & 11.4 & 8.6 & 13.3 & 2.9 & 1.9 & 14.3 & 4.8 & 1.0 & - & 27.6 & 21 & 51.4 \\
\hline $\begin{array}{l}\text { Penicillin } \\
\text { Ampicillin }\end{array}$ & $\leq 8$ & 16 & $\geq 32$ & $0.016-256$ & 7.6 & 5.7 & 28.6 & 5.7 & 6.7 & 21.0 & 11.4 & 1.9 & 5.7 & 2.9 & 1.0 & 1.9 & 27.6 & 15.2 & 57.1 \\
\hline
\end{tabular}

Based on testing of 105 isolates in duplicate on two separate occasions: Chicken feces (CF); retail chicken (RC); soil (SL); feed (FD); minimum inhibitory concentration (MIC); susceptibility (S); Intermediate (I); and Resistance (R). 


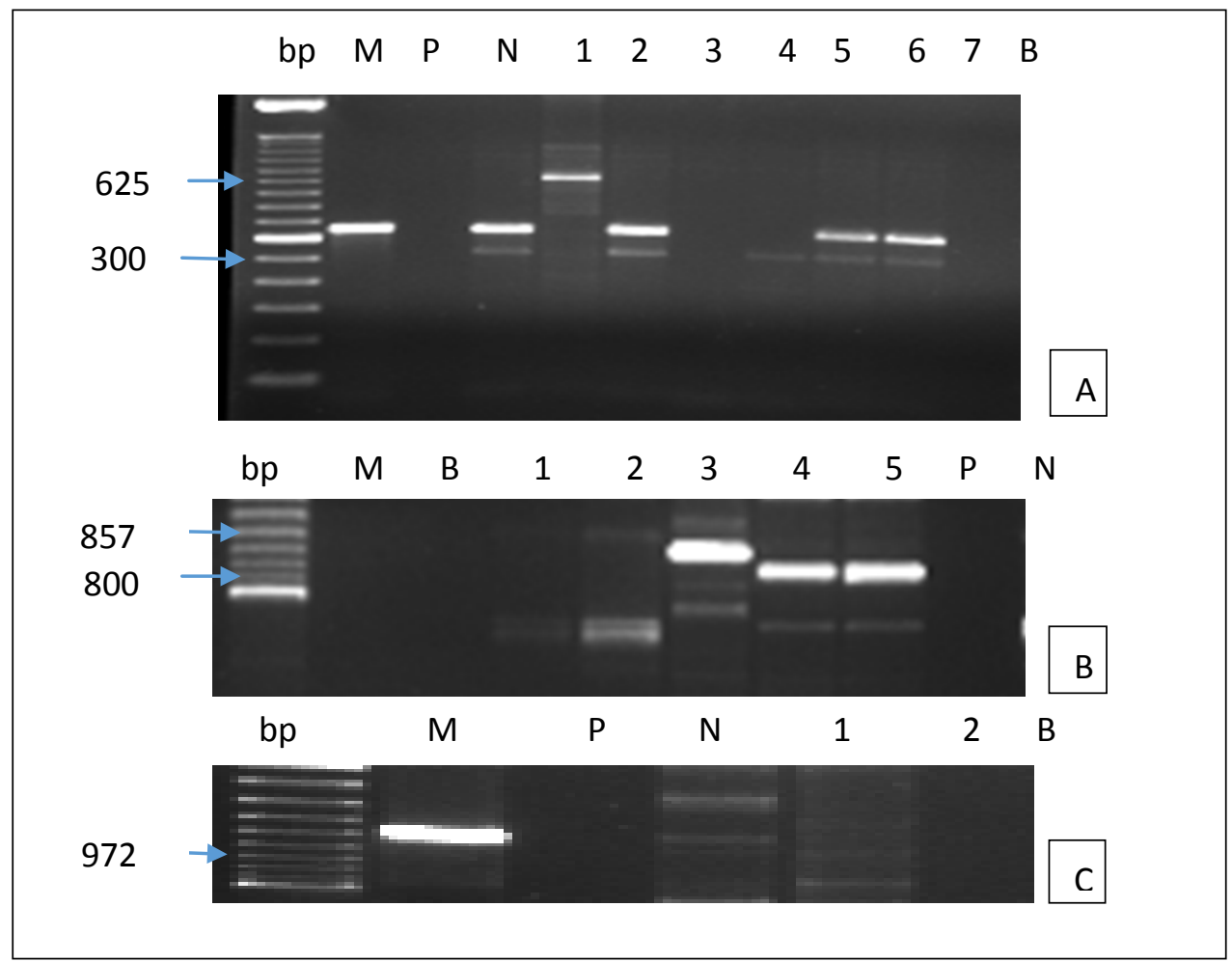

Fig. 1 PCR amplification products generated by primer bla SHV $_{\mathrm{SH}}(\mathrm{A}), b_{\mathrm{CTX} \_\mathrm{M}}(\mathrm{B})$ and $b l a_{\mathrm{TEM}}(\mathrm{C})$ from $E$. coli in small-scaled poultry farms (Lanes 1-7, 1-5 and 1-2, respectively) suspected of being positive for ESBL-producing $E$. coli. Arrows point to the 625, 857, and 972 base pair representing the $b l a_{\mathrm{SHV}}, b a_{\mathrm{CTX}}$ and $b a_{\mathrm{TEM}}$ gene and $\mathrm{M}$ is corresponding weights of the molecular marker (100 kb DNA ladder). Lane $N$ is negative control $E$. coli 11775 and Lane $P$ is positive control ESBL-producing $E$. coli. Lane B is a blank and BP depicts size of DNA fragment in base pairs.

of the genes in a single ESBL-producing E. coli isolate. According to Sebastian et al. [45], ESBL genes including $b l a_{\mathrm{CTX}-\mathrm{M}}, b l a_{\mathrm{TEM}}$ and $b l a_{\mathrm{SHV}}$ are common among in ESBL-producing E. coli. The presence of these genes in E. coli is worrisome; particularly because they cause resistance to carbapenems that are used for the management of infections suspected to be initiated by multidrug-resistant bacteria. Foods of animal origin are therefore, potential reservoirs for ESBL-producing Enterobacteriaceae and their encoding genes positions a critical health risk for consumers [46]. As such, efforts should be concentrated on Best Management Practices (BMPs) and hygienic practices during the course of meat harvesting and processing, to minimize the spread of antimicrobial resistance in the food chain.

\subsection{Antimicrobial Susceptibility of ESBL-Producing Escherichia coli}

Our findings demonstrate that $50.2 \%$ (210 of 418) of the ESBL-producing $E$. coli from poultry farms and retail chicken were resistant to a panel of antibiotics (Table 4). Differences in proportions of ESBL-producing $E$. coli resistant to these antibiotics were high and statistically significant $(p<0.05)$. The occurrence of ESBL producing $E$. coli is a reason for alarm; their multi drug resistance has immensely increased worldwide and reported as one of the most common reasons of morbidity and mortality associated with hospital-acquired infections [47].

Our results established that ESBL positive E. coli isolates from feces demonstrated absolute resistance against erythromycin (100\%; 88 of 88 ) and streptomycin (100\%; 88 of 88 ), which was significantly 
higher than other antibiotics $(p<0.05)$. ESBL positive $E$. coli resistance to streptomycin is widespread among many enteric bacteria [48] and has become a concern to public health. Among the ESBL-producing isolates from feces, high resistance was also observed for tetracycline (88.6\%; 78 of 88 ), followed by kanamycin (86.4\%; 76 of 88), and nalidixic acid (68.2\%; 60 of 88); moderate resistance rates were observed for chloramphenicol (63.6\%; 56 of 88), ampicillin (40.9\%; 36 of 88 ); and relatively low resistance rates were displayed for novobioxn (31.8\%; 28 of 88), vancomycin (29.5\%; 26 of 88), colistin and ciprofloxacin (11.4\%; 10 of 88 ), and amikacin (4.5\%; 4 of 88). Among the ESBL-producing E. coli from retail chicken, highest resistance rates were observed for erythromycin (100\%; 70 of 70 ), followed by streptomycin (88.6\%; 62 of 70$)$, tetracycline $(82.9 \%$; 58 of 70 ), and nalidixic acid (71.4\%; 50 of 70); moderate resistance rates were observed for kanamycin (51.4\%; 36 of 70) and relatively lower resistance rates $(p<0.05)$ were shown for chloramphenicol, ampicillin, colistin, ciprofloxacin, and amikacin (Table 4). None of the isolates from feed showed resistance to chloramphenicol, novobioxn, colistin, ciprofloxacin, and amikacin. ESBL-producing isolates from the soil were not resistant to colistin, ciprofloxacin, and amikacin. Generally, ESBL-producing E. coli from soil and feed generally showed lower resistance as compared to the isolates from feces and retail chicken. If not controlled, diffusion of multidrug resistance from poultry environment to the human community can be a major public health challenge [49]. The rest of the resistance rates among the ESBL-producing E. coli isolates are represented in Table 4.

Several phenotypes among antibiotic-resistant ESBL-producing E. coli isolates are presented in Table 5. Twenty three resistance patterns were observed and the predominant resistant pattern was ERY-STR (30.5\%; 32 of 105), followed by ERY-STR-KAN-NAL (10.5\%, 11 of 105), ERY (7.6\%, 8 of 105), and ERY-STR-KAN-TET-VAN-AMC (6.7\%, 7 of 105). The least $(0.95 \%$; 1 of 105$)$ resistance patterns were

Table 4 Percentage of ESBL-ESBL-producing $E$. coli resistant to select antibiotics.

\begin{tabular}{|c|c|c|c|c|}
\hline \multicolumn{5}{|c|}{ Source of E. coli } \\
\hline Antibiotic & Feces & Chicken & Soil & Feed \\
\hline & \multicolumn{4}{|c|}{ (\%) } \\
\hline CHL & $63.6^{c}$ & $23.1^{\mathrm{d}}$ & $18.2^{\mathrm{b}}$ & $0.0^{\mathrm{e}}$ \\
\hline ERY & $100^{\mathrm{a}}$ & $100^{\mathrm{a}}$ & $81.8^{\mathrm{a}}$ & $46.2^{\mathrm{a}}$ \\
\hline STR & $100^{\mathrm{a}}$ & $88.6^{\mathrm{b}}$ & $86.4^{\mathrm{a}}$ & $23.1^{\mathrm{bc}}$ \\
\hline TET & $88.6^{\mathrm{b}}$ & $82.9^{\mathrm{b}}$ & $80.2^{\mathrm{a}}$ & $30.8^{\mathrm{b}}$ \\
\hline NAL & $68.2^{\mathrm{C}}$ & $71.4^{\mathrm{b}}$ & $4.5^{c}$ & $7.7^{\mathrm{d}}$ \\
\hline KAN & $86.4^{\mathrm{b}}$ & $51.4^{\mathrm{c}}$ & $77.3^{\mathrm{a}}$ & $15.4^{\mathrm{c}}$ \\
\hline VAN & $29.5^{\mathrm{e}}$ & $28.2^{\mathrm{d}}$ & $9.1^{\mathrm{c}}$ & $7.7^{\mathrm{d}}$ \\
\hline NOV & $31.8^{\mathrm{de}}$ & $21.0^{\mathrm{d}}$ & $4.5^{\mathrm{c}}$ & $0.0^{\mathrm{e}}$ \\
\hline COL & $11.4^{\mathrm{f}}$ & $4.7^{\mathrm{e}}$ & $0.0^{\mathrm{d}}$ & $0.0^{\mathrm{e}}$ \\
\hline AMC & $40.9^{\mathrm{d}}$ & $20.5^{\mathrm{d}}$ & $22.7^{\mathrm{b}}$ & $15.3^{\mathrm{c}}$ \\
\hline CIP & $11.4^{\mathrm{f}}$ & $5.1^{\mathrm{e}}$ & $0.0^{\mathrm{d}}$ & $0.0^{\mathrm{e}}$ \\
\hline AMK & $4.5^{\mathrm{g}}$ & $2.6^{\mathrm{e}}$ & $0.0^{\mathrm{d}}$ & $0.0^{\mathrm{e}}$ \\
\hline $\mathrm{N}$ & 88 & 70 & 40 & 12 \\
\hline
\end{tabular}

Antibiotics: chloramphenicol (CHL), erythromycin (ERY), streptomycin (STR), tetracycline (TET), nalidixic acid (NAL), kanamycin (KAN), vancomycin (VAN), novobioxn (NOV), colistin (COL), amoxicillin (AMC), ciprofloxacin (CIP), amikacin (AMK).

a,b,c,d,e,f Means within columns with no common superscript differ $(p<0.05)$.

Table 5 Antimicrobial resistance of ESBL-producing $E$. coli from poultry farms and retail chicken. 


\begin{tabular}{|c|c|c|c|}
\hline $\begin{array}{l}\text { No. of } \\
\text { antimicrobials }\end{array}$ & Most frequent patterns (\% of isolates) & $\begin{array}{l}\text { No. of bacteria } \\
\text { resistance } \\
\text { (\%) }\end{array}$ & Source \\
\hline \multirow{3}{*}{1} & ERY & $8(7.6)$ & FM (5), RC (3) \\
\hline & STR & $2(1.9)$ & FM (1), RC (1) \\
\hline & TET & $1(0.95)$ & FM (1) \\
\hline \multirow{3}{*}{2} & ERY-STR & $32(30.5)$ & FM (26), RC (6) \\
\hline & NAL-TET & $1(0.95)$ & $\mathrm{RC}(1)$ \\
\hline & ERY-TET & $2(1.9)$ & FM (2), RC (0) \\
\hline \multirow{3}{*}{3} & ERY-TET-VAN & $1(0.95)$ & FM (1) \\
\hline & ERY-CHL-STR-NAL & $6(5.7)$ & FM (4), RC (2) \\
\hline & ERY-STR-KAN-NAL & $11(10.5)$ & FM (8), RC (3) \\
\hline \multirow{3}{*}{4} & ERY-STR-TET-VAN & $5(4.8)$ & FM (4), RC (1) \\
\hline & ERY-TET-VAN-AMC & $1(0.95)$ & $\mathrm{RC}(1)$ \\
\hline & ERY-CHL-STR-NOV & $1(0.95)$ & $\mathrm{RC}(1)$ \\
\hline \multirow{6}{*}{6} & CIP-ERY-STR-TET-COL-AMC & $1(0.95)$ & FM (1) \\
\hline & AMK-ERY-STR-NOV-TET-VAN & $5(4.8)$ & FM (4), RC (1) \\
\hline & ERY-STR-KAN-TET-VAN-AMC & $7(6.7)$ & FM (7) \\
\hline & ERY-CHL-STR-KAN-TETR-VAN & $1(0.95)$ & FM (1) \\
\hline & ERY-STR-KAN-TET- VAN-NOV & $5(4.8)$ & FM (3), RC (2) \\
\hline & CIP-ERY-STR-TET-NAL-VAN & $4(3.8)$ & $\mathrm{RC}(4)$ \\
\hline 7 & AMK-ERY-CHL-NAL--TET-VAN-AMC & $3(2.8)$ & FM (1), RC (2) \\
\hline \multirow{2}{*}{8} & CIP-ERY-CHL-STR-NOV-TET-VAN-AMC & $4(3.8)$ & FM (2), RC (2) \\
\hline & AMK-ERY-CHL-KAN-STR-TET-VAN-AMC & $2(1.9)$ & FM (2) \\
\hline 9 & ERY-CHL-STR-NOV-NAL-TET-VAN-COL-AMC & $1(0.95)$ & FM (1) \\
\hline 11 & AMK-CIP-ERY-STR-CHL-KAN-NAL-TET-VAN-COL-AMC & $1(0.95)$ & FM (1) \\
\hline
\end{tabular}

Chloramphenicol (CHL), erythromycin (ERY), streptomycin (STR), tetracycline (TET), nalidixic acid (NAL), kanamycin (KAN), vancomycin (VAN), novobioxn (NOV), colistin (COL), amoxicillin (AMC), ciprofloxacin (CIP), amikacin (AMK).

Source: Farm (FM), retail chicken (RC).

\section{AMK-CIP-ERY-STR-CHL-KAN-NAL-TET-VAN-C} OL, ERY-CHL-STR-NOV-NAL-TET-VAN-COL-AMC, among others. An isolate was considered to be multidrug resistant (MDR) when it displayed resistance to three or more antibiotics [50]. Resistance of ESBL-producing E. coli to erythromycin and tetracycline in this study is a concern; these drugs are approved for treatment of poultry infections [51]. In addition, our result displayed ESBL-producing E. coli resistance to ciprofloxacin and tetracycline, which are commonly used in clinical settings. According to Le et al. [52], contamination of food with antibiotic resistant bacteria is a route to spread ESBL-producing bacteria in communities.

\section{Conclusion}

In conclusion, our findings indicate that poultry farms and retail chicken are potential reservoirs of multi-drug resistant ESBL-producing E. coli. The spread of ESBL-producing E. coli in food animals represents a challenge in food safety and must be reflected as a public health concern, since the transmission to humans is possible. The data from this study provide contextual information for future studies of ESBL-producing $E$. coli trends in small-scaled poultry farms and retail meats. Therefore, further molecular studies are warranted to determine the genetic profile of ESBL-producing $E$. coli from poultry farms and poultry meats.

\section{Acknowledgment}

This work was funded by the U.S. Department of Agriculture, National Institute of Food and Agriculture (Evans-Allen Research Program). The authors thank Mr. Manreet Singh Bhullare for technical support throughout this study.

\section{References}

[1] Furtula, V., Farrell, E. G., Diarrassouba, F., Rempel, H., Pritchard, J., and Diarra, M. S. 2010. "Veterinary Pharmaceuticals and Antibiotic Resistance of Escherichia 
coli Isolates in Poultry Litter from Commercial Farms and Controlled Feeding Trials.” Poult. Sci. 89: 180-8.

[2] Friedman, N. D., Kaye, K. S., Stout, J. E., McGarry, S. A., Trivette, S. L., and Briggs, J. P., et al. 2002. "Health Care-associated Bloodstream Infections in Adults: A Reason to Change the Accepted Definition of Community-Acquired Infections.” Ann. Intern. Med. 137: 791-7.

[3] Duffy, G., Lynch, O. A., and Cagney, C. 2008. “Tracking Emerging Zoonotic Pathogens from Farm to Fork.” Meat Sci. 78: 34-42.

[4] Carattoli, A. 2008. "Animal Reservoirs for Extended Spectrum Beta-Lactamase Producers.” Clin. Microbiol. Infect. 14 (Suppl. 1): 117-23.

[5] Fatemeh, A., Emran, A., Elnaz, K., Mohammad, J. G. S., and Mahboubeh, N. 2012. "The Frequency of Extended Spectrum Beta Lactamase (ESBL) in Escherichia coli and Klebsiella pneumonia: A Report from Mashhad Iran.” J. Med. Bacteriol. 1 (3): 12-1-9.

[6] Silvia, L. M., and Jacoby, A. G. 2014. "Extended Spectrum Beta-Lactamases.” Wolters Kluwer Health.

[7] Habeeb, M. A., Sarwar, Y., Ali, A., Salman, M., and Haque, A. 2013. "Rapid Emergence of ESBL Producers in E. coli Causing Urinary and Wound Infections in Pakistan.” Pak. J. Med. Sci. 29: 540-4.

[8] Sabaté, M., Prats, G., Moreno, E., Ballesté, E., Blanch, A. R., and Andreu, A. 2008. "Virulence and Antimicrobial Resistance Profiles among Escherichia coli Strains Isolated from Human and Animal Wastewater." Res. Microbiol. 159: 288-93.

[9] Collignon, P., Powers, J. H., Chiller, T. M., Aidara-Kane, A., and Aarestrup, F. M. 2009. "World Health Organization Ranking of Antimicrobials According to Their Importance in Human Medicine: A Critical Step for Developing Risk Management Strategies for the Use of Antimicrobials in Food Production Animals." Clin. Infect. Dis. 49: 132-41.

[10] Yusha'u, M., Umar, M. I., and Suleiman, K. 2010. "Indigenous Commercial Drinks as Potential Sources of Extended Spectrum B-Lactamases (ESBLs) Producing Organisms in Kano, Nigeria.” Int. J. Biomed. Health Sci. 6: 103-8.

[11] Geser, N., Stephan, R., and Hächler, H. 2012. "Occurrence and Characteristics of Extended-Spectrum B-Lactamase (ESBL) Producing Enterobacteriaceae in Food Producing Animals, Minced Meat and Raw Milk.” BMC. Vet. Res. 8: 21-9.

[12] Bergenholtz, R. D., Jorgensen, M. S., Hansen, L. H., Jensen, L. B., and Hasman, H. 2009. "Characterization of Genetic Determinants of Extended-Spectrum Cephalosporinases (ESCS) in Escherichia coli Isolates from Danish and Imported Poultry Meat.” J. Antimicrob.
Chemother. 64: 207-9.

[13] Rao, L., Lv, L., Zeng, Z., Chen, S., He, D., Chen, X., et al. 2014. "Increasing Prevalence of Extended-Spectrum Cephalosporin-Resistant Escherichia coli in Food Animals and the Diversity of CTX-M Genotypes during 2003-2012.” Vet. Microbiol. 172: 534-41.

[14] Gao, L., Hu, J., Zhang, X., Ma, R., Gao, J., Li, S., et al. 2014. "Dissemination of ESBL-Producing Escherichia coli of Chicken Origin to the Nearby River Water." $J$. Mol. Microbiol. Biotechnol. 24: 279-85.

[15] CLSI. 2014. "Performance Standards for Antimicrobial Susceptibility Testing: Twenty-Fourth Informational Supplement. M100-S24.” Clinical and Laboratory Standards Institute, Wayne, PA.

[16] Feizabadi, M. M., Delfani, S., Raji, N., Majnooni, A., Aligholi, M., Shahchera, F., et al. 2010. "Distribution of blaTEM, blaSHV, blaCTX-M Genes among Clinical Isolates of Klebsiella pneumoniae at Labbafinejad Hospital, Tehran, Iran.” Microb. Drug Resist. 16 (1): 49-53.

[17] Mahrouki, S., Chihi, H., Bourouis, A., Ben-Moussa, M., Barguellil, F., and Belhadj, O. 2011. "First Characterization in Tunisia of Plasmid Mediated Ampc Beta-Lactamase DHA-1 Coexpressed TEM-24 and Qnra6 in a Multidrug Resistant Proteus Mirabilis Clinical Strain.” Afr. J. Microbiol. Res. 5: 3913-8.

[18] Seyedjavadi, S. S., Goudarzi, M., and Sabzehali, F. 2016. "Relation between $b l a_{\mathrm{TEM}}, b l a_{\mathrm{SHV}}$ and $b l a_{\mathrm{CTX}-\mathrm{M}}$ Genes and Acute Urinary Tract Infections.” J. Acu. Dis. 5: 71-6.

[19] Rodriguez-siek, K. E., Giddings, C. W., Doetkott, C., Johnson, T. J., and Nolan, L. K. 2005. "Characterizing the APEC Pathotype.” Vet. Res. 36: 241-56.

[20] Puno-Sarmiento, J., Gazal, L. E., Medeiros, L. P., Nishio, E. K., Kobayashi, R. K. T., and Nakazato, G. 2014. "Identification of Diarrheagenic Escherichia coli Strains from Avian Organic Fertilizers.” Inter. J. Environ. Res. Pub. Health 11: 8924-39.

[21] Cohen, N., Ennaji, H., Bouchrif, B., Hassar, M., and Karib, H. 2007. “Comparative Study of Microbiological Quality of Raw Poultry Meat at Various Seasons and Different Slaughtering Process in Casablanca (Morocco).” J. Appl. Poult. Res. 16: 502-8.

[22] Zhao, C., Ge, B., De Villena, J., Sudler, R., Yeh, E., Zhao S., et al. 2001. "Prevalence of Campylobacter spp., Escherichia coli, and Salmonella serovars in Retail Chicken, Turkey, Pork, and Beef from the Greater Washington, D.C. Area.” Appl. Environ. Microbiol. 67: 5431-6.

[23] Van der Bogaard, A. E., and Stobberingh, E. E. 2000. "Epidemiology of Resistance to Antibiotics. Links between Animals and Humans." Int. J. Antimicrob. Agents 14: 327-35. 
[24] Trawińska, B., Polonis, A., Tymczyna, L., Popiołek-Pyrz, M., Bombik, T., and Saba, L. 2006. "Bacteriological and Parasitological Pollution of the Environment and Birth Health State around the Reproductive Layer Farm.” Ann. Univ. M. Curie Skłodowska. Sec. EE. 24: 371-6.

[25] Blaak, H., Aham, H., Hamidjaja, R. A., Plaats R. Q. J., Kerkhof-de Heer, L., de Roda Husman, A. M., et al. 2015. "Distribution, Numbers, and Diversity of ESBL-Producing E. coli in the Poultry Farm Environment.” PLoS ONE 10 (8): e0135402.

[26] Crump, J. A., Griffin, P. M., and Angulo, F. J. 2002. "Bacterial Contamination of Animal Feed and Its Relationship to Human Foodborne Illness.” Clin. Infect. Dis. 35 (7): 859-65.

[27] Costa, D., Vinue, L., Poeta, P., Coelho, A. C., Matos, M., Saenz, Y., et al. 2009. "Prevalence of Extended-Spectrum Beta-Lactamase-Producing Escherichia coli Isolates in Faecal Samples of Broilers.” Vet Microbiol. 138: 339-44.

[28] Heuer, H., Schmitt, H., and Smalla, K. 2011. “Antibiotic Resistance Gene Spread due to Manure Application on Agricultural Fields.” Curr. Opin. Microbiol. 14: 236-43.

[29] Machado, E., Coque, T. M., Canton, R., Sousa, J. C., and Peixe, L. 2008. “Antibiotic Resistance Integrons and Extended-Spectrum ß-Lactamases among Enterobacteriaceae Isolates Recovered from Chickens and Swine in Portugal." J. Antimicrob. Chemother. 62: 296-302.

[30] Egea, P., Lopez-Cerero, L., Torres, E., Gomez-Sanchez Mdel, C., Serrano, L., Navarro Sanchez-Ortiz, M. D., et al. 2012. "Increased Raw Poultry Meat Colonization by Extended Spectrum Beta-Lactamase-Producing Escherichia coli in the South of Spain.” Int. J. Food Microbiol. 159: 69-73.

[31] Cohen, S. J., Munckhof, T., Voets, G., Scharringa J., Fluit, A., and Leverstein-Van Hall, M. 2012. "Comparison of ESBL Contamination in Organic and Conventional Retail Chicken Meat.” Int. J. Food Microbiol. 154: 212-14.

[32] Pitout, J. D., and Laupland, K. B. 2008. "Extended-Spectrum Beta-Lactamase-Producing Enterobacteriaceae: An Emerging Public-Health Concern.” Lancet Infect Dis. 8: 159-66.

[33] Blaak, H., van Hoek, A. H., Hamidjaja, R. A., van der Plaats, R. Q., Kerkhof-de Heer, L., de Roda Husman, A. M., et al. 2015. "Distribution, Numbers, and Diversity of ESBL-Producing E. coli in the Poultry Farm Environment.” PLoS One 10 (8): e0135402.

[34] Horton, R. A., Randall, L. P., Snary, E. L., Cockrem, H., Lotz, S., Wearing, H., et al. 2011. "Fecal Carriage and Shedding Density of CTX-M Extended-Spectrum B-Lactamase-Producing Escherichia coli in Cattle,
Chickens, and Pigs: Implications for Environmental Contamination and Food Production.” Appl. Environ. Microbiol. 77: 3715-9.

[35] Laube, H., Friese, A., von Salviati, C., Guerra, B., and Rosler, U. 2014. "Transmission of ESBL/AmpC-Producing Escherichia coli from Broiler Chicken Farms to Surrounding Areas.” Vet. Microbiol. 172: 519-27.

[36] Forsberg, K. J., Reyes, A., Wang, B., Selleck, E. M., Sommer, M. O., and Dantas, G. 2012. "The Shared Antibiotic Resistome of Soil Bacteria and Human Pathogens.” Sci. 337: 1107-11.

[37] Chang, Q., Wang, W., Regev-Yochay, G., Lipsitch, M., and Hanage, W. P. 2015. “Antibiotics in Agriculture and the Risk to Human Health: How Worried Should We Be?” Evol. Appl. 8 (3): 240-7.

[38] U.S. Food and Drug Administration. 2013. “Guidance for Industry 213. New Animal Drugs and New Animal Drug Combination Products Administered in or on Medicated Feed or Drinking Water of Food Producing Animals: Recommendations for Drug Sponsors for Voluntarily Aligning Product Use Conditions with GFI \#209.” U.S. Food and Drug Administration, Center for Veterinary Medicine, Silver Spring. MD.

[39] Hur, J., Jawale, C., and Lee, J. H. 2012. “Antimicrobial Resistance of Salmonella Isolated from Food Animals: A Review.” Food Res. Int. 45: 819-30.

[40] Samaha-Kfoury, J. N., and Araj, G. F. 2003. "Recent Developments in $\beta$-Lactamases and Extended Spectrum $\beta$-Lactamases.” BMJ 327: 1209-13.

[41] Seiffert, S. N., Hilty, M., Perreten, V., and Endimiani, A. 2013. "Extended-Spectrum Cephalosporin Resistant Gram-Negative Organisms in Livestock: An Emerging Problem for Human Health?” Drug Resist. 16: 22-45.

[42] Akond, M. A., Alam, S., Hassan, S. M. R., and Shirin, M. 2009. "Antibiotic Resistance of Escherichia coli Isolated from Poultry and Poultry Environment of Bangladesh.” Am. J. Environ. Sci. 5: 47-52.

[43] Zhang, H., Zhai, Z., Li, Q., Liu, L., Guo, S., Li, Q., et al. 2016. "Characterization of Extended-Spectrum $\beta$-Lactamase-Producing Escherichia coli Isolates from Pigs and Farm Workers.” J. Food Prot. 79 (9): 1630-4.

[44] Livermore, D. M., Canton, R., Gniadkowski, M., Nordmann, P., Rossolini, G. M., Arlet, G., et al. 2007. "CTX-M: Changing the Face of ESBLs in Europe." $J$. Antimicrob. Chemother 59 (2): 165-74.

[45] Sebastian, G., Ewers, C., and Wieler, L. H. 2011. "Extended-Spectrum Beta-Lactamases Producing E. coli in Wildlife, Yet Another Form of Environmental Pollution?” Front. Microbiol. 2: 246.

[46] Tekiner, S. H., and Özpınar, H. 2016. "Occurrence and Characteristics of Extended Spectrum 

Escherichia coli from Small-Scaled Poultry Farms and Retail Chicken

Beta-Lactamases-Producing Enterobacteriaceae from Foods of Animal Origin.” Braz. J. Microbiol. 47: 444-51.

[47] Kumar, D., Singh, A. K., Ali, M. R., and Chander, Y. 2014. "Antimicrobial Susceptibility Profile of Extended Spectrum $\beta$-Lactamase (ESBL) Producing Escherichia coli from Various Clinical Samples.” Infect. Dis. 7: 1-8.

[48] Bass, L., Liebert, C. A., Lee, M. D., Summers, A. O., White, D. G., Thayer, S. G., et al. 1999. "Incidence and Characterization of Integrons, Genetic Elements Mediating Multiple-Drug Resistance, in Avian Escherichia coli.” Antimicrob. Agents Chemother 43 (12): 2925-9.

[49] Harada, K., and Asai, T. 2010. "Role of Antimicrobial Selective Pressure and Secondary Factors on Antimicrobial Resistance Prevalence in Escherichia coli from Food-Producing Animals in Japan.” J. Biomed Biotechnol 2010: 180682.
[50] Magiorakos, A. P., Srinivasan, A., Carey, R. B., Carmeli, Y., Falagas, M. E., Giske, C. G., et al. 2012. "Multidrug-Resistant, Extensively Drug-Resistant and Pandrug-Resistant Bacteria: An International Expert Proposal for Interim Standard Definitions for Acquired Resistance.” Clin. Microbiol. Infect. 18: 268-81.

[51] McEwen, S. A., and Fedorka-Cray, P. J. 2002. “Antimicrobial Use and Resistance in Animals." Clin. Infect. Dis. 34: 93-106.

[52] Le, Q. P., Ueda, S., Nguyen, T. N., Dao, T. V., Van Hoang, T. A., Tran, T. T., et al. 2015. "Characteristics of Extended-Spectrum B-Lactamase-Producing Escherichia coli in Retail Meats and Shrimp at a Local Market in Vietnam.” Foodborne Pathog. Dis. 12 (8): 719-25. 